Products and Services In Practice is provided to readers using text and images from the manufacturer, supplier or distributor and does not imply endorsement by $B D J$ In Practice. Normal and prudent research should be exercised before purchase or use of any product mentioned.

Please send product and services news through to David Westgarth, BDJ In Practice via: David.Westgarth@bda.org

\section{Don't let your practice reach the news for the wrong reasons}

A recent news piece has revealed that over 500 patients have been recommended to get tests for HIV and other bloodborne diseases following the use of unclean equipment at a dental practice in Hertfordshire.

As well as being a scary time for these patients, this once again highlights the importance of proper infection control in dental practices. Make sure you're compliant and are protecting your patients from these risks by using a trusted autoclave such as the Little Sister SES 2020N from Eschmann.

Able to accommodate five full size instrument trays and perform rapid cycles with active drying, the autoclave is fully geared towards the needs of the modern professional.

For more information on the highly effective and affordable range of decontamination equipment and products from Eschmann, please visit www. eschmann.co.uk, follow on Twitter at @ LittleSisterSES or call 01903753322.

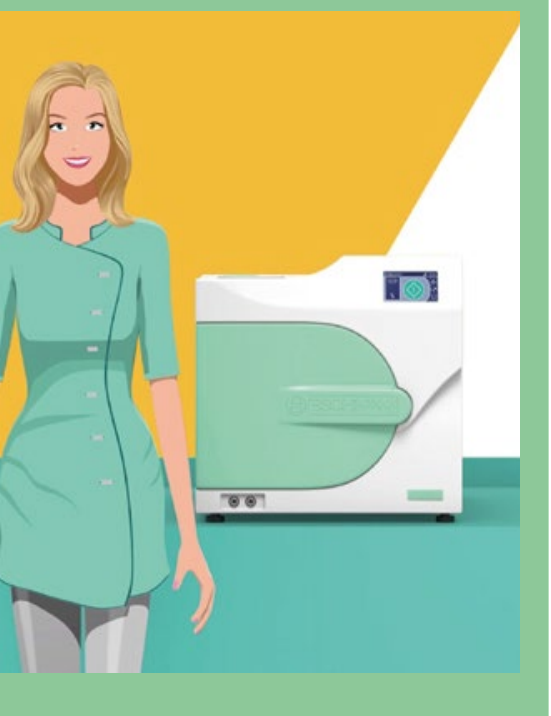

\title{
A new development
}

Dürr Dental have developed an extended version of their VistaVox S panoramic machine which contains six additional programmes for time-saving cephalometric exposure with minimum radiation doses, called VistaVox S Ceph.

As you'd expect from Dürr, exceptional diagnostics and ease of use are guaranteed. Alongside the 17 panoramic programmes, the VistaVox S Ceph has several orthodontic applications, including 'Lateral Head, 'Full Lateral Head', 'PA Head' and 'Waters View'. The unit is as fast as it is smart - with a scan time of just 1.9 seconds, images are exceptionally sharp using the lowest possible radiation dose. This functionality is afforded by the high-sensitivity CSL sensors. The unit can effortless switch between the

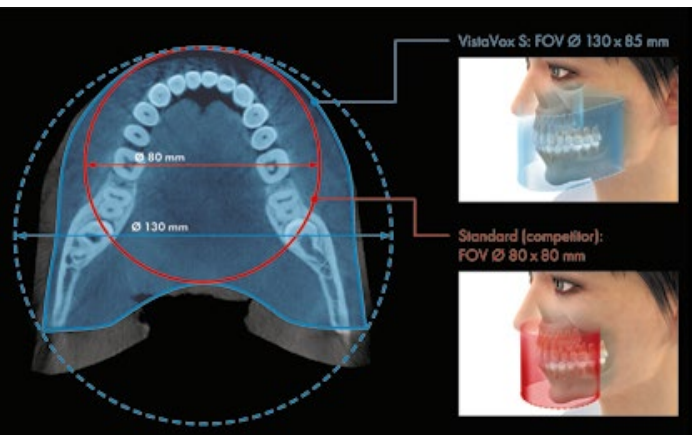

3D X-Ray and the Ceph boom, a process that on some machines can be both cumbersome and risky.

Just like the VistaVox $\mathrm{S}$ it has a perfect $3 \mathrm{D}$ imaging volume of $130 \mathrm{~mm}$ (compared to $80 \times 80 \mathrm{~mm}$ for most other systems). This means it completely covers the whole diagnostically relevant area, including the rear molars, an essential requirement for diagnosing an impacted wisdom tooth. Enhanced visibility does not require a higher radiation dose; in fact, the opposite is true. A special curved path, which rotates $540^{\circ}$, in combination with a tightly collimated fan beam and a highly sensitive Csl sensor, means that a particularly low radiation dose is used.

Similarly to the VistaVox $\mathrm{S}$, this enhanced model offers $50 \mathrm{x}$ $50 \mathrm{~mm}$ volumes, for indications that only require a certain part of the jaw region to be shown, e.g. for endodontic or implant treatments. The unit offers true all-in-one capabilities for a full range of diagnostics making it ideal for dentists, orthodontists or those who work within larger practices offering a full range of specialist treatments.

\section{Predictable excellence}

A patient experiencing pain and in need of endodontic treatment might still be reluctant to go ahead.

Root canal therapy has a bad reputation; that it is painful and unpleasant.

Reassure your patients by only using the very best tools and materials. COLTENE has a comprehensive range of premium products, from rotary files to sealing materials, which facilitate the treatment pathway and help to ensure predicable, stable results.

COLTENE is the mark of excellence. When you use COLTENE products in your endodontic work, you can assure nervous patients of a successful treatment that will improve their quality of life. They should accept nothing less - and neither should you.

To find out more visit www.coltene.com, emailinfo.uk@coltene.com or call 01444 235486. 